\title{
Pluricentrismo no ensino de Alemão como Língua Estrangeira: uma proposta para análise de material didático
}

\author{
[Pluricentrism in the teaching of German as a foreign language: an analysis proposal of \\ teaching material] \\ http://dx.doi.org/10.11606/1982-883723411
}

Mônica Maria Guimarães Savedra ${ }^{1}$

Camila Meirelles ${ }^{2}$

\begin{abstract}
In this article we address the pluricentrism of the German language by performing a literature review on the subject that focuses on variants and varieties of German. After a historical retrospective based on a pluricentric notion of teaching German as a Foreign Language, we propose an analysis of teaching material with six categories. Three categories are based on the Common European Framework of Reference for Languages: competence, subject and text source, and three refer to basic questions of the DACH-Prinzip: discursive topics of pluricentricity, approach, and pluricentric variety. The results of implementing this analysis with the proposed categories indicate a relative incipient awareness of the German language as a pluricentric language used in different centers.
\end{abstract}

Keywords: Pluricentrism; DACH-Prinzip; German as foreign language; DaF Kompakt Neu

Resumo: Neste artigo abordamos o pluricentrismo da língua alemã através de uma revisão da literatura sobre o tema que privilegia os estudos sobre variantes e variedades do alemão. Após uma retrospectiva histórica, a partir de uma noção pluricêntrica para o ensino de Alemão como Língua Estrangeira, apresentamos uma proposta para análise de material didático a partir de seis categorias. Três categorias são baseadas no Quadro Europeu Comum de Referência para as Línguas: competência, tema e tipo de fonte textual, e três se referem às questões de base do DACH-Prinzip: tópicos discursivos de pluricentricidade, abordagem e variedade pluricêntrica. Os resultados da implementação da análise com as categorias propostas apontam para uma relativa

\footnotetext{
${ }^{1}$ Universidade Federal Fluminense, Departamento de Letras Estrangeiras Modernas, Rua Professor Marcos Waldemar de Freitas Reis, s/n, Campus do Gragoatá, Niterói, RJ, 24210-350, Brasil. E-Mail: msavedra@id.uff.br. ORCID: 0000-0003-1056-9391

${ }^{2}$ Universidade Federal Fluminense, Departamento de Letras Estrangeiras Modernas, Rua Professor Marcos Waldemar de Freitas Reis, s/n, Campus do Gragoatá, Niterói, RJ, 24210-350, Brasil. E-Mail: camilameirelles@id.uff.br. ORCID: 0000-0003-3075-3014

O presente trabalho foi realizado com apoio da Fundação Carlos Chagas Filho de Amparo à Pesquisa do Estado do Rio de Janeiro (FAPERJ), com apoio do Conselho Nacional de Desenvolvimento Científico e Tecnológico (CNPq) e com apoio da Coordenação de Aperfeiçoamento de Pessoal de Nível Superior Brasil (CAPES) - Código de Financiamento 001.
}

(cc) BY-NC

Pandaemonium, São Paulo, v. 23, n. 41, set.-dez. 2020, p. 1-23 
SAVEDRA, M.M.G.; MeIRELleS, C. - Pluricentrismo no ensino de Alemão como Língua Estrangeira

incipiência da conscientização da língua alemã como língua pluricêntrica em uso em diferentes centros.

Palavras-Chave: Pluricentrismo; DACH-Prinzip; alemão como língua estrangeira; DaF kompakt neu

\section{Introdução}

O presente artigo surge de questionamentos sobre a condição pluricêntrica da Língua Alemã (LA) no âmbito dos estudos que vêm sendo desenvolvidos no Laboratório de Pesquisa em Contato Linguístico da UFF (LABPEC-UFF). Partimos da premissa de que é relevante abordar os aspectos apresentados no documento da IDV (Internationaler Deutschlehrerinnen- und Deutschlehrerverband) ${ }^{3}$ que descreve o DACH-Prinzip (IDV 2013) e nas publicações recentes que apontam o DACH-Landeskunde como elemento complementar daquele (ALTMAYER 2013; FISCHER; FRISCHHERZ; NOKE 2010) nos cursos de Licenciatura para formação de professores de Alemão como Língua Estrangeira (ALE). Tendo em vista que o material didático possui lugar central no processo de ensinoaprendizagem (cf. RÖSLER; SCHART 2016; UPHOFF 2009) propomos neste artigo a análise de um material didático utilizado para cursos de graduação em Português-Alemão em universidades públicas do Brasil.

Inicialmente procedemos a uma revisão bibliográfica sobre o tema do pluricentrismo a partir de estudos seminais que privilegiam a LA e, em seguida, delimitamos as categorias de análise propostas para identificar aspectos de pluricentricidade da LA no material didático implementado no locus determinado. Por fim, apresentamos os resultados da investigação adotada.

\section{Alemão como língua pluricêntrica}

O termo pluricentrismo linguístico é introduzido por Heinz Kloss (1976) a partir dos conceitos de Abstand- e Ausbausprache (KLOSS 1967 apud SAVEDRA 2015). Posteriormente, Michael Clyne (1992) desenvolve o conceito ao identificar 17 línguas como sendo pluricêntricas em uma obra clássica que se torna referência na área:

\footnotetext{
${ }^{3}$ Associação Internacional de Professores de Alemão

Pandaemonium, São Paulo, v. 23, n. 41, set.-dez. 2020, p. 1-23
} 
SAVEDRA, M.M.G.; MeIRELleS, C. - Pluricentrismo no ensino de Alemão como Língua Estrangeira

"Pluricentric Languages: Differing Norms in Different Nations". Ammon, partindo dos estudos germanísticos introduzidos por Riesel (1964) e retomando os estudos de Kloss (op. Cit.) e Clyne (op. Cit.), publica em 2004 o primeiro dicionário de variantes da LA: o Variantenwörterbuch des Deutschen, atualizado em 2018.

O conceito de língua pluricêntrica que utilizamos é o que está explicado na introdução do dicionário de Ammon et al. (2018). Para os autores, uma língua pluricêntrica é aquela que é língua nacional ou regional em mais de um centro.

Países ou regiões são considerados centros de uma língua pluricêntrica quando desenvolvem suas próprias especificidades linguísticas, ou seja, quando apresentam uma norma padrão própria e função oficial. Centros podem ser países ou regiões onde se constituíram especificidades linguísticas próprias (AMMON et al. 2018). No caso das línguas pluricêntricas, mais comumente, cada variedade nacional é representada por um centro.

De acordo com a terminologia científica corrente, uma nação (Áustria, por exemplo) ou uma comunidade linguística que faz parte de uma nação (Suíça alemã, por exemplo) que apresenta uma variedade (nacional) própria (variedade nacional) de uma língua, deve ser chamada de centro linguístico nacional ou centro nacional de uma língua. (AMMON 1995: 95, tradução nossa, grifo do autor). ${ }^{4}$

No tocante à LA, Ammon et al. (2018) citam sete centros ou regiões onde ela é língua oficial, são eles:

- Alemanha, Áustria e Liechtenstein - como única língua oficial;

- Suíça e Luxemburgo - como uma de outras línguas oficiais (sendo elas na Suíça:

Francês, Italiano e Romanche; em Luxemburgo: Francês e Luxemburguês);

- Leste da Bélgica (Ostbelgien) e Tirol do Sul no norte da Itália na província de Bolzano - como língua regional oficial.

Além desses centros, a LA é falada em outras regiões e reconhecida como língua minoritária em outros países como Austrália, Brasil, Camarões, Croácia, Dinamarca, Eslováquia, Eslovênia, Estônia, EUA, França, Hungria, Letônia, Lituânia, Moldávia,

\footnotetext{
${ }^{4}$ Im Einklang mit dem gängigen wissenschaftlichen Sprachgebrauch soll eine Nation (Beispiel Österreich) oder eine Sprachgemeinschaft als Teil einer Nation (Beispiel deutschsprachige Schweiz), die über eine eigene (nationale) Varietät (Nationalvarietät) einer Sprache verfügt, nationales Sprachzentrum oder nationales Zentrum einer Sprache heißen.
}

Pandaemonium, São Paulo, v. 23, n. 41, set.-dez. 2020, p. 1-23 
SAVEDRA, M.M.G.; MEIRELlES, C. - Pluricentrismo no ensino de Alemão como Língua Estrangeira

Namíbia, Holanda, Paraguai, Polônia, República Tcheca, Romênia, Rússia, Tajiquistão, Togo e Ucrânia (SAVEDRA 2016).

Os autores do dicionário identificam para a LA os seguintes centros: Vollzentren, Halbzentren e Viertelzentren.

Os Vollzentren possuem suas especificidades linguísticas padrão codificadas em obras próprias, como dicionários. No caso da LA, Ammon et al. (2018) consideram a Alemanha, a Áustria e a Suíça como Vollzentren.

Os Halbzentren, por outro lado, não possuem codificação própria, se orientando pelas normas de outra variedade nacional, geralmente de um Vollzentrum vizinho. Para os autores, Liechtenstein, Luxemburgo, Leste da Bélgica e Tirol do Sul são vistos como Halbzentren.

Os Viertelzentren são aqueles países e regiões onde a língua alemã é reconhecida como língua minoritária (podendo possuir, ou não, particularidades linguísticas distintas), mas não possui status de língua oficial nacional.

É importante ressaltar que as variedades de uma língua pluricêntrica (e, por conseguinte, suas variantes) são equivalentes. “A concepção pluricêntrica da língua alemã significa que especificidades linguísticas [variantes] dos centros da língua alemã não são consideradas como desvio de uma língua standard alemã, mas sim como formas standard equivalentes da língua"” (AMMON et al., 2018: XLI, tradução nossa).

Apesar disso, os autores afirmam que a variedade nacional da Alemanha é dominante em relação às outras. "A variedade da Alemanha é mais conhecida em outros centros do que vice-versa, o que faz com que alguns Teutonismen [variantes específicas utilizadas na Alemanha] sejam cada vez mais reconhecidos como gemeindeutsch" (AMMON et al. 2018: XLI-XLII, tradução nossa) ${ }^{6}$. Gemeindeutsch se refere às palavras ou expressões utilizadas indistintamente em todos os países de LA (op. cit.).

Em virtude de fatores históricos, políticos e econômicos, as diferentes variedades nacionais de uma língua pluricêntrica não recebem o mesmo tratamento, tendo

\footnotetext{
${ }^{5}$ Die plurizentrische Auffassung von der deutschen Sprache bedeutet, dass sprachliche Besonderheiten der Zentren des Deutschen nicht als Abweichungen von einer übergreifenden deutschen Standardsprache gelten, sondern als gleichberechtigt nebeneinander bestehende standardsprachliche Ausprägungen des Deutschen.

${ }^{6}$ Daher ist das deutsch Deutschlands in den anderen Zentren auch besser bekannt als umgekehrt, was dazu führt, dass manche ,Teutonismen' (Besonderheiten Deutschlands) zunehmend gemeindeutsche Geltung gewinnen.
}

Pandaemonium, São Paulo, v. 23, n. 41, set.-dez. 2020, p. 1-23 
SAVEDRA, M.M.G.; MeIRELleS, C. - Pluricentrismo no ensino de Alemão como Língua Estrangeira

normalmente um status assimétrico (AMMON 1989; CLYNE 2004). Isso ocorre também no caso da LA como especifica Hägi (2006):

Sem dúvidas, a variedade teutônica da língua alemã é dominante devido ao seu tamanho, força econômica e importância política em relação às variedades austríaca e suíça. Isso significa, entre outras coisas, que Teutonismen [variantes específicas da Alemanha], de modo geral, são mais conhecidos e inteligíveis na Áustria e na Suíça alemã do que, ao contrário, Austriazismen [variantes específicas da Áustria] e Helvetismen [variantes específicas da Suíça] na Alemanha. Outra característica dessa assimetria é que o alemão da Alemanha é considerado, sobretudo por austríacos e suíços, como mais correto, com maior prestígio e com maior potencial funcional - principalmente nas ciências, literatura, teatro e artes (HÄGI 2006: 275-276, tradução nossa). ${ }^{7}$

Como vimos nas afirmações acima, a questão do pluricentrismo linguístico envolve não somente aspectos (socio)linguísticos da variação, mas também aspectos históricos, políticos e glotopolíticos. Lagares (2018) explica, de modo claro, tais questões ao tratar da norma e da oficialização de línguas: "Uma língua é oficializada quando, do ponto de vista jurídico, é considerada adequada para ser usada em todas as atividades políticas e administrativas de um país" (LAGAREs 2018: 62). Assim, línguas oficiais, utilizadas em diversos domínios linguísticos - esferas políticas, institucionais, educacionais e na mídia, por exemplo - possuem uma norma padrão, codificada de forma distinta nos diferentes centros.

\section{De $A B C D$ a $D A C H(L)$ : uma retrospectiva histórica para o}

\section{ensino de ALE}

Uma noção pluricêntrica da LA aparece no ensino de ALE, mais especificamente no ensino de Landeskunde, a partir da década de 1980, através de um primeiro encontro em 1988 entre representantes das associações de professores da República Federal da

\footnotetext{
${ }^{7}$ Zweifelsohne ist aufgrund der Größe, wirtschaftlichen Stärke und politischen Bedeutung Deutschlands die deutschländische Varietät gegenüber dem österreichischen Deutsch und dem Schweizer Hochdeutschen dominant. Das bedeutet u. a. auch, dass Teutonismen in der Regel in Österreich und der Deutschschweiz bekannter und verständlicher sind als umgekehrt Austriazismen und Helvetismen in Deutschland. Ein weiteres Merkmal dieser Asymmetrie ist, dass das deutschländische Deutsch nicht zuletzt auch von österreichischer und Schweizer Seite häufig - vor allem in Wissenschaft, Belletristik, Theater und Kunstgesang - als das korrektere, prestigehaftere und funktional leistungsstärkere eingestuft wird.
}

Pandaemonium, São Paulo, v. 23, n. 41, set.-dez. 2020, p. 1-23 
SAVEDRA, M.M.G.; MeIRELleS, C. - Pluricentrismo no ensino de Alemão como Língua Estrangeira

Alemanha (BRD), República Democrática Alemã (DDR), Áustria e Suíça (KRUMM 2017), culminando na publicação das ABCD-Thesen zur Rolle der Landeskunde (ABCD-THESEN 1990). Essa publicação apresenta uma tentativa de aproximação entre os Estados envolvidos em sua elaboração, e, ao mesmo tempo, uma busca de semelhanças e cooperação. Além disso, elas contribuíram para uma nova orientação em relação ao ensino integrado de Landeskunde (FISCHER; FRISCHHERZ; NOKE 2010), se ocupando mais com uma visão intercultural do que com uma mera apresentação de fatos (KRUMM 2017).

De acordo com as $A B C D$-Thesen, Landeskunde é um princípio que se concretiza através da combinação do ensino linguístico e informação cultural e é feito por meio de atividades específicas integradas à aula de alemão. Nesse sentido, a abordagem dos fenômenos tanto nacionais como regionais dos países de língua alemã deve ser feita de forma contrastiva, por meio de exemplos (ABCD-THESEN 1990).

$\mathrm{O}$ artigo apresenta 22 teses que dissertam sobre o papel da Landeskunde na aula de alemão. Iniciado com uma pequena definição do conceito Landeskunde, o documento é ainda dividido em três partes: princípios gerais (allgemeine Grundsätze), princípios didáticos-metodológicos (Didaktisch-methodische Grundsätze) e possibilidades de cooperação (Möglichkeiten der Koopertation).

Em 1992, um grupo de trabalho D-A-CH-L (D-A-CH-L-Arbeitsgruppe) foi constituído pela IDV com o objetivo de promover seminários envolvendo os países de língua alemã (KRUMM 2017).

A partir desses seminários e encontros, outro conceito começou a se formar, intitulado D-A-CH-Konzept (SHAFER 2018), elaborado de modo trinacional como um conceito didático de Landeskunde integrativo e intercultural (SIG 2.4 2017: 7). O D-ACH-Konzept se baseia em uma perspectiva pluricêntrica da LA, principalmente em relação às diferenças entre os países de LA, como uma forma de conscientização, de maneira apenas receptiva.

O foco central na aula é uma conscientização de forma receptiva no tocante ao vocabulário e à fonologia. [...] Isso significa uma ênfase principalmente da recepção, e não da produção de variantes linguísticas pelos aprendizes (SIG 2.4 2017: 3, tradução nossa) ${ }^{8}$.

\footnotetext{
${ }^{8}$ Im Unterricht steht eine rezeptive Bewusstmachung bzgl. Wortschatz und Aussprache im Zentrum. [...] Es geht also dezidiert in erster Linie um das Rezipieren und nicht Produzieren sprachlicher Vielfalt durch die Lernenden.
}

Pandaemonium, São Paulo, v. 23, n. 41, set.-dez. 2020, p. 1-23 
SAVEDRA, M.M.G.; MeIRELleS, C. - Pluricentrismo no ensino de Alemão como Língua Estrangeira

No decorrer da década de 1990, diversas iniciativas, visando um trabalho conjunto para fomentar a língua alemã em relação ao ensino e à formação de professores, tomaram forma, como a elaboração da prova de proficiência Zertifikat-Deutsch (equivalente ao nível $\mathrm{B}^{9}$ ) de forma trinacional pelas instituições Goethe-Institut, ÖSD, telc e Schweizer Erziehungsdirektorenkonferenz ${ }^{10}$ (SHAFER 2018; KRUMM 2010).

Em 2007 o DACHL-Arbeitsgruppe foi reestruturado, tendo como função, principalmente, fortalezar a rede de contatos e o trabalho em conjunto das organizações e representantes dos países de língua alemã: Áustria, Alemanha, Suíça e Liechtenstein (DEMMING; HÄGI; SCHWEIGER 2013). Outra atividade desse grupo de trabalho é a manutenção da organização de seminários (DACHL-Seminare), a cada dois anos nos quatro países, para professores associados à $I D V$.

A partir do trabalho do DACHL-Arbeitsgruppe, o DACH-Prinzip começou a se estruturar e foi publicado em 2008 (SHAFER 2018). O DACH-Prinzip se baseia no reconhecimento da diversidade dos países e regiões de LA no âmbito do ensino de alemão e de Landeskunde, da produção de materiais didáticos, assim como da formação de professores (IDV 2013).

Na implementação [do DACH-Prinzip], isto significa - num esforço conjunto para apoiar e promover o ensino de alemão em todo o mundo - a inclusão de forma equivalente das variadas dimensões linguísticas e socioculturais dos países de língua alemã no âmbito das pesquisas científicas, das atividades das organizações, do desenvolvimento de conceitos e projetos, assim como em todas as formas de apresentação de atividades específicas, mas especialmente na prática de ensino (DEMMING; HÄGI; SCHWEIGER, 2013: 11-12, tradução nossa) ${ }^{11}$.

\footnotetext{
${ }^{9}$ De acordo com o Quadro Europeu Comum de Referência para Línguas - QECR (CONSELHO DA EUROPA, 2001).

${ }^{10}$ A prova atualmente chama-se Goethe-Zertifikat B1 ou ÖSD-Zertifikat B1. O certificado é desenvolvido em conjunto pelo ÖSD - Österreiches Sprachdiplom Deutsch (Áustria), Goethe-Institut (Alemanha) e Lernund Forschungszentrum (Centro de ensino e pesquisa) da Universidade de Freiburg na Suíça e é aplicado pelo ÖSD (https://www.osd.at/die-pruefungen/osd-prufungen/oesd-zertifikat-b1-zb1/ Acesso em 21/10/2019), assim como pelo Goethe-Institut. (https://www.goethe.de/ins/br/de/sta/poa/prf/gzb1/ueb.html Acesso em 21 out. 2019).

${ }^{11}$ In der Umsetzung bedeutet dies - im gemeinsamen Bemühen um die Stützung und Förderung des Deutschunterrichts weltweit - die gleichwertige Einbeziehung der unterschiedlichen sprachlichen und landeskundlichen Dimensionen des deutschsprachigen Raumes im Rahmen wissenschaftlicher Arbeiten, in Aktivitäten der Mittlerorganisationen, in der Entwicklung von Konzepten und Projekten sowie in allen Formen der Präsentation fachlicher Aktivitäten, vor allem aber auch in der Praxis des Unterrichts.
}

Pandaemonium, São Paulo, v. 23, n. 41, set.-dez. 2020, p. 1-23 
SAVEDRA, M.M.G.; MeIRELleS, C. - Pluricentrismo no ensino de Alemão como Língua Estrangeira

O DACH-Prinzip deve ser entendido como um conceito aberto e flexível, orientado no contexto de ensino de ALE levando-se em consideração os interesses, objetivos e necessidades dos alunos - e, por isso mesmo, com uma variada gama de possibilidades de realização, o que reflete em vários aspectos. Essa flexibilidade se refere também ao manejo de textos, temas e conteúdos (SIG 2.4 2017: 9).

Há um número significativo de publicações em LA na presente década, tanto em relação ao pluricentrismo quanto à sua abordagem no ensino de ALE, como a obra DACH-Landeskunde: Theorie-Geschichte-Praxis organizada por Demmig, Hägi e Schweiger (2013) que traz diversas contribuições acerca do tema. Em um dos artigos presentes na compilação, Pupp Spinassé e Bredemeier (2013) traçam um panorama da presença do DACH-Konzept no Brasil, principalmente em relação a aspectos de Landeskunde e seu ensino integrado ao ensino da LA.

A temática do pluricentrismo e a cooperação entre os países de LA (DACHLLänder) passa a ser tema constante dos encontros do Congresso Internacional de Professores de Alemão (IDT: Internationale Tagung der Deutschlehrerinnen und Deutschlehrer), o qual acontece a cada quatro anos (SORGER 2013; JARZĄBEK 2013a).

Com base em relatos disponíveis na literatura de ALE (SHAFER 2018; JARZĄBEK 2013b), temos o tema do pluricentrismo assim abordado: em 2001 no IDT, que aconteceu em Lucerna, Suíça, o tema aparece em uma sessão intitulada Deutsch als plurizentrische Sprache (Alemão como Língua Pluricêntrica); em 2005 em Graz na Áustria, o IDT contou também como uma sessão Deutsch als plurizentrische Sprache (Alemão como Língua Pluricêntrica) e em 2009 em Jena com o Podium das D-A-CH-Konzept. Em 2013 em Bozen, além de uma sessão intitulada Plurizenrtik (Pluricentrismo), o evento contou com forte presença dos países de língua alemã (DACHL-Länder) e com a publicação dos anais do encontro em livro (DRUMBL; CARVALHO; KLINNER 2016).

O tema continua em evidência e no último congresso internacional, que aconteceu em 2017, em Fribourg, na Suíça, foi debatido nas sessões DACH-Landeskunde e Sprachliche Variation im Deutschen (Variação linguística no alemão). Assim como o evento de Bozen, o IDT 2017 contou com uma publicação, o que permite maior visibilidade desse assunto no âmbito dos estudos e pesquisas de ALE. Vale ainda ressaltar que o Pluricentrismo é inserido como sessão de debate nos congressos da ABRAPA, como em 2015 e 2018, por exemplo, na sessão Sprachenpolitik (Políticas Linguísticas).

Pandaemonium, São Paulo, v. 23, n. 41, set.-dez. 2020, p. 1-23 
SAVEDRA, M.M.G.; MeIReLleS, C. - Pluricentrismo no ensino de Alemão como Língua Estrangeira

\section{Categorias para uma análise de aspectos de pluricentricidade} em um material didático para ensino de ALE

No presente artigo analisamos o DaF kompakt neu Al - Kursbuch und Übungsbuch, por ser o material didático atualmente adotado nos cursos de Letras Português-Alemão das três universidades onde há a formação de professores de ALE no Rio de Janeiro (UERJ, UFF e UFRJ).

O material DaF kompakt neu Al da editora Klett, cuja central está localizada na cidade de Stuttgart na Alemanha, é composto por livro do curso (Kursbuch), livro de exercícios (Übungsbuch) e CDs de áudio. Além disso, é possível adquirir separadamente o manual do professor (Lehrerhandbuch) e materiais adicionais de estudo como Intensivtrainer - Wortschatz und Grammatik e Vokabeltrainer. O material também está disponível em versão virtual (para Tablet) e exercícios complementares são disponibilizados online no website da editora.

O DaF Kompakt neu A1 é composto por oito lições divididas em três partes, Teil A, Teil B e Teil C. Ao final de cada lição do Kursbuch é apresentada uma lista de todo vocabulário abordado na lição (Lektionswortschatz), assim como as principais frases e expressões usadas na comunicação e um breve resumo da gramática (Redemittel/ Grammatik). O Übungsbuch também está dividido em oito lições que abordam as três partes do Kursbuch (Teil A, B, C). Após cada lição no Übungsbuch são propostas outras atividades complementares (DaF kompakt - mehr entdecken) para produção oral e escrita, além de exercícios de fonética (Phonetik).

Foram submetidos à análise o livro do curso e o livro de exercícios, e também os arquivos de áudio contidos nos CDs e o manual do professor. Este último fornece dados relevantes sobre a concepção do material didático e seus objetivos e apresenta planos de aula para cada lição com explicações sobre as atividades contidas no Kursbuch. O manual do professor traz ainda exercícios adicionais (Kopiervorlagen) complementares às lições, que podem ser utilizados em sala de aula.

Para esta investigação, foram criadas seis categorias pluricêntricas de análise com o objetivo de identificar nas atividades selecionadas a presença de aspectos pluricêntricos. 
SAVEdRA, M.M.G.; MeIRELleS, C. - Pluricentrismo no ensino de Alemão como Língua Estrangeira

As três primeiras (competência, tema e tipo de fonte de texto) foram categorizadas a partir do que é preconizado no QECR, como explicitado a seguir.

A primeira categoria refere-se à competência trabalhada na atividade. No contexto de ensino de ALE quatro competências básicas são mais frequentes: Lesen, Hören, Schreiben e Sprechen (RÖSLER, 2012; FAISTAUER, 2010). A categoria competência foi, portanto, escolhida, por ser amplamente utilizada em materiais didáticos e provas de proficiência, principalmente após a publicação do QECR (CONSELHO DA EUROPA 2001).

De acordo de Faistauer (2010), as competências possuem uma função dupla na aula de língua estrangeira, elas atuam tanto como objetivo quanto como meio para o aprendizado da língua, pois são além de um recurso para a aprendizagem, o próprio meio de comunicação.

Ao lado das quatro competências básicas - Lesen, Hören, Schreiben e Sprechenoutros conhecimentos linguísticos, como aspectos gramaticais e vocabulário, foram identificados quando aparecem nas atividades e foram avaliados isoladamente.

Essa primeira categoria permite, por conseguinte, correlacionar as atividades de cunho pluricêntrico com as competências trabalhadas no material didático.

A segunda categoria escolhida para a análise foi o tema. No QECR estão descritas áreas temáticas, que "constituem o centro do discurso, da conversa, da reflexão ou da composição, como centros de atenção de determinados actos comunicativos" (CONSELHO DA EUROPA 2001: 83).

Fora dos países de língua alemã, os textos e temas contidos nos materiais didáticos representam uma forma central de acesso à língua e cultura estrangeira e, com isso, definem em quais situações e por meio de quais textos a língua alemã pode ser aprendida e colocada em prática em sala de aula (KRUMM 2010: 1215-1216, tradução nossa $)^{12}$.

A escolha dos temas contidos nos materiais didáticos é importante, visto que muitas vezes o livro é o principal representante da língua e cultura alvo para alunos (e também professores) que aprendem o idioma no exterior e não podem viajar

\footnotetext{
${ }^{12}$ Außerhalb des deutschsprachigen Raumes stellen die in Lehrwerken enthaltenen Texte und Themen den zentralen Zugang zur fremden Sprache und Kultur dar und legen damit fest, in welchen Situationen, mit welchen Texten die deutsche Sprache im Unterricht erlernt und praktiziert werden kann.
} 
SAVEDRA, M.M.G.; MeIRELleS, C. - Pluricentrismo no ensino de Alemão como Língua Estrangeira

frequentemente para os países onde a língua é falada, como, por exemplo, alunos brasileiros aprendendo a LA (UPHOFF 2009). Como um dos pilares da aula de língua estrangeira, os conteúdos dos materiais didáticos são importantes veículos de informação sobre outras culturas e, portanto, influenciam a imagem da cultura alvo no exterior (MAIJALA 2007).

O tipo de fonte do texto também foi considerado na análise, a partir da classificação proposta no QCER: textos autênticos (A), semi-autênticos (SA) e não autênticos (NA). Consideramos como textos autênticos aqueles "produzidos para fins comunicativos e não para o ensino da língua" (CONSELHO DA EUROPA 2001: 204). Foram classificados como semi-autênticos, "textos concebidos para parecerem textos autênticos" (Ibid.), ou seja, que poderiam existir em uma situação comunicativa real, mas que foram produzidos para fins didáticos. Textos sem indicação de fonte também foram classificados como semi-autênticos. Consideramos como textos não autênticos explicações no material didático, assim como trechos ou frases descontextualizadas, como "frases isoladas para fazer exercícios (fonéticos, gramaticais, etc.)" (ibid.).

As próximas categorias (tópicos discursivos, abordagem e variedade pluricêntrica) foram elaboradas a partir dos pressupostos do DACH-Prinzip, como explicado a seguir.

A categoria tópicos discursivos de pluricentricidade faz referência a aspectos linguísticos e culturais (Landeskunde) entre as variedades nacionais dos países de fala alemã. Na presente análise, concebemos como Landeskunde não só a apresentação de fatos sobre os países e regiões de língua alemã, como também a presença de textos, autores e conteúdos oriundos ou que remetam a esses países ou regiões.

É importante destacar que uma concepção mais abrangente de Landeskunde se faz urgente e necessária no ensino de ALE. Altmayer et al. (2019) propõem o conceito "Landeskunde discursiva" (diskursive Landeskunde). O objeto de estudo de uma Landeskunde discursiva não está presente em uma realidade objetiva, mas sim em manifestações linguísticas, mais especificamente em padrões de interpretação (Deutungsmuster) utilizados no discurso e suas significações (ALTMAYER et al. 2019).

No que se refere aos aspectos linguísticos, vale destacar que entre as variedades nacionais da língua alemã, variações linguísticas são mais frequentes no léxico e na fonologia e menos na morfologia e sintaxe, estando presentes também na pragmática e 
SAVEDRA, M.M.G.; MeIRELleS, C. - Pluricentrismo no ensino de Alemão como Língua Estrangeira com poucos exemplos na ortografia. (AMMON et al. 2018; SHAFER 2018; SPIEKERMANN 2010; AUER 2014).

A quinta categoria elaborada para análise, abordagem, considera dois tipos: uma explícita (E) e outra implícita (I), podendo também aparecer de forma combinada, nesses casos, optamos por identificar a abordagem predominante. Na abordagem explícita, o tema pluricentrismo e as variantes e variedades dos países de língua alemã são apresentadas de forma direta, por exemplo, por meio de comparações. Portanto, essa abordagem "se configura como uma reflexão consciente, orientada culturalmente sobre a pluralidade do objeto de estudo Alemão/DACHL" (SIG 2.4 2017: 9, tradução nossa) ${ }^{13}$. Já a abordagem implícita é caracterizada por "um uso evidente, não marcado, de textos, conteúdos, variedades, autores, etc. de toda região DACHL [países de língua alemã], sem que essa seleção seja tematizada de forma explícita ou estimule comparações internas" (Ibid., tradução nossa) ${ }^{14}$.

Com a categoria variedade pluricêntrica identificamos o país ou região contemplado na atividade proposta pelo material didático. Os países foram identificados da seguinte forma: A - Áustria, D - Alemanha, CH - Suíça. Na análise do material DaF Kompakt neu A1 não foram encontradas referências a outros países ou regiões de LA além dos citados acima.

Para análise com base nas seis categorias delimitadas, foram selecionadas todas as atividades do Kursbuch e do Übungsbuch que abordam personagens, temas, textos, autores e variantes que remetam a diferentes usos linguísticos e culturais em países ou regiões onde a LA é falada. A atividade correspondente foi selecionada quando a variante específica aparece discriminada, ou quando o material didático chama a atenção para alguma distinção entre as variantes usadas nas diferentes variedades de LA. Textos autênticos, com a fonte especificada, também estão contemplados na análise, visto que são oriundos de algum país ou região de fala alemã.

$\mathrm{Na}$ tabela a seguir estão listadas as atividades selecionadas referentes ao Kursbuch. Além das seis categorias descritas acima, a primeira coluna se refere à

\footnotetext{
${ }^{13}[\ldots]$ zeichnet sich durch eine bewusste, kulturwissenschaftlich orientierte Reflexion über die Pluralität des Gegenstands „Deutsch/DACHL“ aus.

${ }^{14}$ [...] unmarkierter Einsatz von Texten, Inhalten, Varietäten, Autor/- innen etc. aus dem ganzen DACHLRaum gemeint, ohne diese Auswahl bewusst zu thematisieren oder binnenkontrastive Vergleiche anzuregen.
}

Pandaemonium, São Paulo, v. 23, n. 41, set.-dez. 2020, p. 1-23 
SAVEDRA, M.M.G.; MeIRELleS, C. - Pluricentrismo no ensino de Alemão como Língua Estrangeira

identificação da atividade no livro. As lições estão identificadas por L + número da lição, ou seja, L1 = Lição 1; a seguir a parte da lição (A, B ou C) é precedida de T (Teil); o exercício é identificado por Ü (Übung) seguido pelo número correspondente. Assim, L1TBÜ3 corresponde à lição 1 , parte $\mathrm{B}$, exercício 3.

Quadro 1 - Atividades Kursbuch- DaF Kompakt neu A1

\begin{tabular}{|c|c|c|c|c|c|c|}
\hline Atividade & Competência & Tema & Fonte & $\begin{array}{c}\text { Tópicos } \\
\text { discursivos de } \\
\text { pluricentricidade }\end{array}$ & Abordagem & $\begin{array}{c}\text { Variedade } \\
\text { pluricêntrica }\end{array}$ \\
\hline L1TBÜ3 & Lesen & $\begin{array}{c}\text { Informações } \\
\text { pessoais }\end{array}$ & SA & Landeskunde & $\mathrm{E}$ & $\mathrm{CH}$ \\
\hline L1TCÜ4 & Hören & $\begin{array}{c}\text { Informações } \\
\text { pessoais }\end{array}$ & SA & Landeskunde & I & $\mathrm{D}$ \\
\hline L2TBÜ3 & Lesen & $\begin{array}{l}\text { Relações } \\
\text { pessoais }\end{array}$ & SA & Landeskunde & I & $\mathrm{D}$ \\
\hline L2TCÜ1 & Lese/Hören & Comida & SA & Landeskunde & I & A \\
\hline L2TCÜ2 & Lesen/Hören & Comida & SA & $\begin{array}{c}\text { Landeskunde / } \\
\text { lexical }\end{array}$ & $\mathrm{E}$ & $\mathrm{A} / \mathrm{D}$ \\
\hline L3TB- & Lesen & Compras & NA & Landeskunde & $\mathrm{E}$ & $\mathrm{A} / \mathrm{CH} / \mathrm{D}$ \\
\hline L3TCÜ1 & $\begin{array}{c}\text { Lesen/ } \\
\text { Sprechen }\end{array}$ & Turismo & A & Landeskunde & I & $\mathrm{D}$ \\
\hline L4TAÜ1 & Lesen/Hören & Vida cotidiana & SA & Landeskunde & I & $\mathrm{D}$ \\
\hline L5TBÜ1 & Lesen & Esporte & SA & Landeskunde & I & D \\
\hline L5TCÜ1 & Lesen & Esporte & SA & Landeskunde & I & $\mathrm{D}$ \\
\hline L5TCÜ3 & $\begin{array}{c}\text { Lesen/ } \\
\text { Schreiben }\end{array}$ & Esporte/ & SA & Landeskunde & I & D \\
\hline L6TAÜ1 & Lesen/Hören & Moradia & SA & Landeskunde & I & $\mathrm{D}$ \\
\hline L7TCÜ4 & Lesen/Hören & Linguagem & A & Landeskunde & I & A \\
\hline L8TAÜ1 & Hören & Turismo & SA & $\begin{array}{l}\text { Landeskundel } \\
\text { fonológico }\end{array}$ & $\mathrm{E}$ & $\mathrm{A} / \mathrm{CH} / \mathrm{D}$ \\
\hline L8TAÜ2 & Hören & Turismo & SA & $\begin{array}{c}\text { Landeskundel } \\
\text { lexical/fonológico }\end{array}$ & $\mathrm{E}$ & $\mathrm{CH}$ \\
\hline L8TAÜ4 & Hören & Lugares & SA & $\begin{array}{c}\text { Landeskundel } \\
\text { lexical/fonológico }\end{array}$ & $\mathrm{E}$ & $\mathrm{A} / \mathrm{CH} / \mathrm{D}$ \\
\hline L8TAÜ5 & Sprechen & Lugares & SA & Landeskunde & I & $\mathrm{CH}$ \\
\hline L8TBÜ1 & $\begin{array}{l}\text { Sprechen/ } \\
\text { Hören }\end{array}$ & $\begin{array}{c}\text { Relações } \\
\text { pessoais }\end{array}$ & SA & Landeskunde & $\mathrm{E}$ & $\mathrm{CH} / \mathrm{D}$ \\
\hline
\end{tabular}


SAVEDRA, M.M.G.; MeIRELleS, C. - Pluricentrismo no ensino de Alemão como Língua Estrangeira

\begin{tabular}{ccccccc} 
L8TBÜ2 & $\begin{array}{c}\text { Lesen } \\
\text { Lesen/ }\end{array}$ & $\begin{array}{c}\text { Relações } \\
\text { pessoais }\end{array}$ & SA & Landeskunde & E & CH \\
\hline Vida cotidiana & A & Landeskunde & I & CH \\
L8TCÜ1 & Hören & Lugares & SA & $\begin{array}{c}\text { Landeskundel } \\
\text { ortografico/ } \\
\text { fonológico }\end{array}$ & E & CH \\
L8TCÜ3 & $\begin{array}{c}\text { Lesen } \\
\text { Hören/ }\end{array}$ & $\begin{array}{c}\text { Informações } \\
\text { pessoais }\end{array}$ & SA & Landeskunde & I & $\mathrm{CH}$ \\
L8TCÜ4 & $\begin{array}{c}\text { Arte } \\
\text { Sprechen }\end{array}$ & A-SA & Landeskunde & I & $\mathrm{CH}$ \\
\hline
\end{tabular}

Fonte: Compilação das autoras

O Kursbuch apresenta um total de 115 atividades e mais oito listas de vocabulário no final das lições. Na tabela acima constam as 24 atividades selecionadas do Kursbuch que atenderam aos critérios estabelecidos. A última atividade, identificada como L8-LW, corresponde à lista de vocabulário (Lektionswortschatz) que consta ao final da lição 8.

As competências mais trabalhadas nas atividades selecionadas são Lesen e Hören. Uma explicação para isso é que as competências receptivas são geralmente mais trabalhadas que as produtivas em níveis iniciais.

Em relação ao tema das atividades, observamos uma seleção variada, que acompanha o tema geral proposto na lição, com assuntos frequentes em um material didático de nível A1.

A maior parte das atividades apresenta textos semi-autênticos que simulam situações reais de comunicação, mas que foram adaptados ou mesmo produzidos para o DaF Kompakt neu Al, o que também pode ser atribuído ao fato do material ser voltado ao nível iniciante.

Podemos relacionar os tópicos discursivos de pluricentricidade com o tipo de abordagem. As atividades com abordagens explícitas contêm, em sua maioria, uma comparação do tópico lexical. De modo geral, aspectos culturais (Landeskunde) aparecem de forma implícita, sem que uma comparação entre variedades ou mesmo países seja tematizada. 
SAVEDRA, M.M.G.; MeIRELleS, C. - Pluricentrismo no ensino de Alemão como Língua Estrangeira

A Suíça e suas respectivas variantes possuem lugar de destaque no material analisado, principalmente na lição 8 , que explora um campo temático relacionado à cidade de Berna. As variantes lexicais da Suíça $(\mathrm{CH})$ destacadas no material aparecem em comparação com as variantes da Alemanha (D) e da Áustria (A).

A segunda atividade da lição 8 (identificada na tabela como L8TAÜ2), que se passa em Berna, na Suíça, exemplifica a análise apresentada. A atividade foi considerada como semi-autêntica por simular uma situação de comunicação real, que poderia ocorrer nos países de fala alemã.

Figura 1 - Kursbuch A1- L8TAÜ2

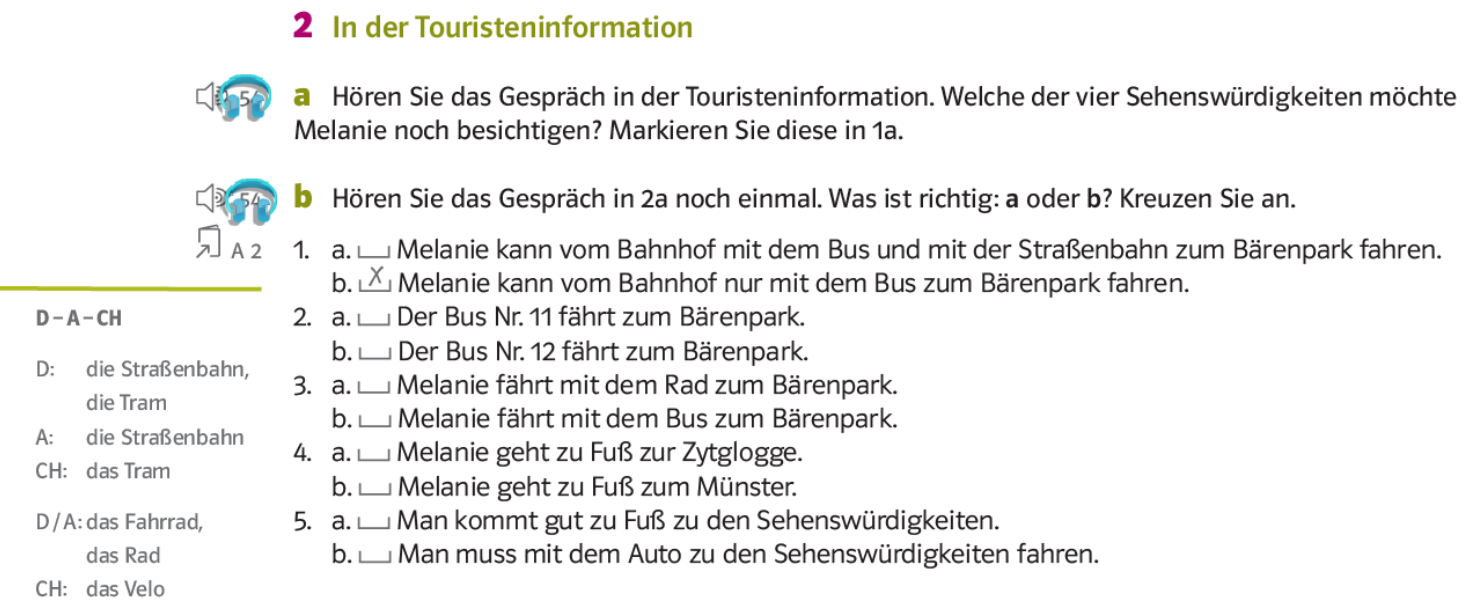

Fonte: BRAUN et al. (2016: 66)

No áudio de um minuto e doze segundos há duas interlocutoras: Melanie, que está visitando a cidade, e uma funcionária que fornece informações turísticas. A funcionária, cuja fala tem uma leve melodia e entonação típicas da variedade padrão suíça, utiliza-se de algumas variantes específicas suíças como Grüezi, Velo e Ade. Além disso, há a menção de pontos turísticos da cidade, como Bärenpark, Münster e Zytglogge (Zeitglockenturm).

Além das informações trazidas pelo material através do áudio, uma comparação explícita de variantes lexicais é apresentada junto à atividade, com o título D-A-CH. Em relação ao meio de transporte, a variante Straßenbahn é atribuída à Alemanha e à Áustria, enquanto que die Tram, com a forma feminina, é indicada como variante da Alemanha (D) e das Tram, com o artigo neutro, é apresentada como a variante da Suíça (CH). Entretanto, tal informação apresentada no DaF Kompakt não é comprovada no dicionário de Ammon et al. (2018: 749. Para os autores, a variante feminina die Tram ocorre na 
SAVEDRA, M.M.G.; MeIRELleS, C. - Pluricentrismo no ensino de Alemão como Língua Estrangeira

Áustria (A) e no nordeste e sudeste da Alemanha (D) e a variante neutra das Tram ocorre na Suíça (CH). Outras variantes como das Fahrrad, das Rad (Alemanha e Áustria) e das Velo (Suíça) também aparecem contrastivamente. A variante Fahrrad é considerada por Ammon et al. (2018: 220) como gemeindeutsch, ou seja, variante comum a todos os países de língua alemã, e não específica da Alemanha e da Áustria. Isso significa que, ao lado de Velo, variante específica, a variante Fahrrad também ocorre na Suíça, sendo concorrentes. Embora sejam ambas obras de publicação recente (o dicionário é publicado em 2018 e o livro DaF Kompakt neu em 2016), para que possamos ter uma resposta precisa quanto ao uso de tais variantes nos diferentes centros de LA, faz-se necessário o desenvolvimento de uma pesquisa sociolinguística no locus.

O Übungsbuch conta com um total de 155 atividades. Destas, 29 correspondem aos critérios propostos nesta análise e estão apresentadas na tabela a seguir.

Quadro 2 - Atividades Übungsbuch - DaF Kompakt neu Al

\begin{tabular}{|c|c|c|c|c|c|c|}
\hline Atividade & Competência & Tema & Fonte & $\begin{array}{c}\text { Tópicos } \\
\text { discursivos de } \\
\text { pluricentricidade }\end{array}$ & Abordagem & $\begin{array}{c}\text { Variedade } \\
\text { pluricêntrica }\end{array}$ \\
\hline L1TCÜ3 & Lesen/Hören & Educação & $\mathrm{A} / \mathrm{AS}$ & Landeskunde & I & $\mathrm{D}$ \\
\hline L1MEÜ1 & Lesen & Educação & AS & Landeskunde & I & $\mathrm{D}$ \\
\hline L2TCÜ2 & Vocabulário & Vida cotidiana & NA & lexical & I & $\mathrm{D}$ \\
\hline L2TCÜ3 & Vocabulário & Comida & NA & lexical & I & $\mathrm{A} / \mathrm{D}$ \\
\hline L3TAÜ4 & Lesen & Educação & AS & Landeskunde & I & D \\
\hline L3TBÜ1 & Vocabulário & Comida & NA & lexical & I & $\mathrm{D}$ \\
\hline L3TBÜ2 & Vocabulário & Comida & NA & lexical & I & $\mathrm{D}$ \\
\hline L3TBÜ4 & $\begin{array}{c}\text { Lesen/ } \\
\text { Sprechen }\end{array}$ & Educação & $\mathrm{A} / \mathrm{AS}$ & Landeskunde & I & $\mathrm{D}$ \\
\hline L3TCÜ1 & Gramática & Vida cotidiana & NA & Landeskunde & I & $\mathrm{D}$ \\
\hline L3MEÜ3 & $\begin{array}{c}\text { Lesen/ } \\
\text { Schreiben }\end{array}$ & Turismo & AS & Landeskunde & I & $\mathrm{D}$ \\
\hline L4TCÜ4 & Lesen & $\begin{array}{l}\text { Serviços/ } \\
\text { Empresa }\end{array}$ & AS & Landeskunde & I & $\mathrm{D}$ \\
\hline L4MEÜ3 & $\begin{array}{l}\text { Lesen/ } \\
\text { Sprechen }\end{array}$ & $\begin{array}{c}\text { Iniciativas } \\
\text { intelectuais e } \\
\text { artísticas }\end{array}$ & A & Landeskunde & $\mathrm{E}$ & $\mathrm{D} / \mathrm{A}$ \\
\hline L5TBÜ1 & Lesen & Esporte & AS & Landeskunde & I & $\mathrm{D}$ \\
\hline
\end{tabular}


SAVEDRA, M.M.G.; MeIRELleS, C. - Pluricentrismo no ensino de Alemão como Língua Estrangeira

\begin{tabular}{|c|c|c|c|c|c|c|}
\hline L5TCÜ1 & Lesen/Hören & Esporte & AS & Landeskunde & I & D \\
\hline L5MEÜ3 & $\begin{array}{c}\text { Lesen/ } \\
\text { Sprechen }\end{array}$ & Tempo livre & A & Landeskunde & I & $\mathrm{D}$ \\
\hline L6TAÜ1 & Schreiben & $\begin{array}{c}\text { Informações } \\
\text { pessoais }\end{array}$ & AS & Landeskunde & I & $\mathrm{D}$ \\
\hline L6MEÜ1 & Schreiben & Arte & A & Landeskunde & I & D \\
\hline L7TAÜ3 & Lesen & Vida cotidiana & AS & Landeskunde & I & $\mathrm{D}$ \\
\hline L7TCÜ7 & Lesen & $\begin{array}{c}\text { Informações } \\
\text { pessoais }\end{array}$ & AS & Landeskunde & I & A \\
\hline L8TAÜ1 & Lesen & Viagem & AS & Landeskunde & I & $\mathrm{CH}$ \\
\hline L8TAÜ3 & $\begin{array}{c}\text { Vocabulário/ } \\
\text { Lesen/ } \\
\text { Gramática }\end{array}$ & Lugares & AS & Landeskunde & I & $\mathrm{CH}$ \\
\hline L8TAÜ4 & $\begin{array}{l}\text { Vocabulário/ } \\
\text { Lesen }\end{array}$ & Vida cotidiana & AS & Landeskunde & I & $\mathrm{CH}$ \\
\hline L8TBÜ3 & Lesen & Museu/ Arte & NA/AS & Landeskunde & I & $\mathrm{CH}$ \\
\hline L8TBÜ4 & Lesen & Comida & AS & Landeskunde & I & $\mathrm{CH}$ \\
\hline L8TCÜ1 & Lesen & Vida cotidiana & AS & Landeskunde & I & $\mathrm{CH}$ \\
\hline L8TCÜ2 & $\begin{array}{c}\text { Lesen/ } \\
\text { Gramática }\end{array}$ & Lugares & NA & Landeskunde & I & $\mathrm{CH}$ \\
\hline L8TCÜ3 & Lesen & $\begin{array}{c}\text { Informações } \\
\text { pessoais }\end{array}$ & AS & Landeskunde & I & $\mathrm{CH}$ \\
\hline L8TCÜ4 & Lesen & Arte & A & Landeskunde & I & $\mathrm{CH}$ \\
\hline
\end{tabular}

Fonte: Compilação das autoras

Nas atividades do Übungsbuch encontramos mais textos não autênticos do que no Kursbuch. O que não é de se admirar, posto que no livro texto é onde os conteúdos são apresentados e no de exercícios somente treinados. No que se refere à abordagem, no Übungsbuch a grande maioria dos exercícios, com exceção apenas de um, apresenta uma abordagem implícita.

O exercício que identificamos como tendo uma abordagem explícita pode ser visualizado a seguir. 
SAVEDRA, M.M.G.; MeIRELleS, C. - Pluricentrismo no ensino de Alemão como Língua Estrangeira

Figura 2 - Übungsbuch A1 - L4MEÜ3

\section{Miniprojekt: Wirtschaft trifft Kultur}

Bilden Sie zwei Gruppen. Gruppe A recherchiert über die Adolf Würth $\mathrm{GmbH} \& \mathrm{Co}$. KG in Künzelsau, Gruppe B über die Freilichtspiele in Schwäbisch Hall. Finden Sie Antworten zu den Fragen unten und präsentieren Sie im Kurs.

"Ich mag dich!"

„das Rössl“ (A) von

"das Ross" $=$ "das Pferd"

freilichtspiele-hall.de

$\underline{\text { wuerth.com }}$

Seit wann gibt es das Unternehmen?

Wo gibt es das Unternehmen?

Mitarbeiter?

Umsatz?

Engagement? Kultur?

Programm/Spielplan? Welche Stücke?

Premieren?

Wann ist/war das?

Kontaktdaten?

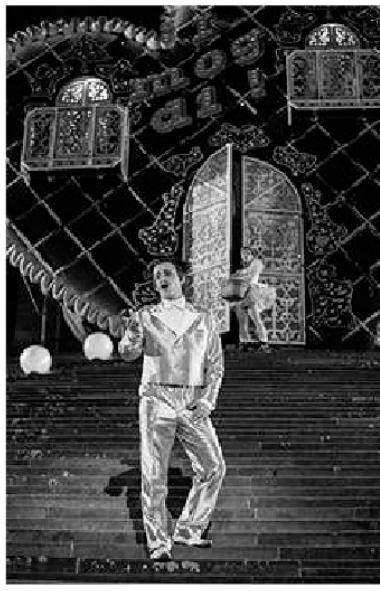

Szene aus "Im weißen Rössl“ (2013)

Fonte: BRAUN et al. (2016: 106)

A atividade propõe uma pesquisa a ser feita na internet sobre a empresa Würth (cuja sede está localizada em Künzelsau, Alemanha) e sobre o teatro Freilichtspiele (em Schwäbisch Hall, também na Alemanha), e, em seguida, a apresentação das informações coletadas. A foto que acompanha a atividade é do musical "Im weißen Rössl", escrito pelo compositor austríaco Ralph Benatzky (a informação sobre a composição do musical não acompanha a atividade). Ao lado do exercício encontramos indicações de variantes da Áustria (A) explicitamente apresentadas como tais.

Outro exemplo que também pode ser discutido à luz da variação pluricêntrica está na lição 2, como apresentado a seguir.

Figura 3 - ̈̈bungsbuch A1 - L2TCÜ2

\section{Die Wochentage}

Für den 6. Wochentag gibt es zwei Namen:

Samstag oder

Sonnabend.

a Lesen Sie die Abkürzungen in der Anzeige vom „Brunnenstüberl“ im Kursbuch $1 a$. Schreiben Sie die Wochentage.

$\begin{array}{llll}\text { 1. } \mathrm{Mo} & \text { 3. Mi } & \text { 5. Fr } & \text { 7. So } \\ \text { 2. } \mathrm{Di} & \text { 4. Do Donnerstag } & \text { 6. Sa_ }\end{array}$

Fonte: BRAUN et al. (2016: 88)

De acordo a obra em referência, a variante Sonnabend é específica do Norte e Centro da Alemanha. Essa especificidade não é marcada no material didático analisado, dando a impressão de ser uma variante comum a todos os países de LA (gemeindeutsch). 
SAVEDRA, M.M.G.; MeIRELleS, C. - Pluricentrismo no ensino de Alemão como Língua Estrangeira

Finalmente, vale registrar ainda algo sobre o manual do professor do livro $D a F$ kompakt neu, que apresenta, após uma breve parte introdutória, indicações sobre as lições e exercícios extras, que podem ser copiados (Kopiervorlage).

Na parte inicial, são apresentados o grupo-alvo ao qual o material se destina, a estrutura das lições e descrições sobre atividades e jogos propostos pelo material. $\mathrm{O}$ manual do professor indica como grupo-alvo pessoas que estudam ou trabalham na Alemanha, Áustria Suíça ou Liechtenstein e gostariam de atingir o nível B1 rapidamente (SANDER; SCHÄFER 2017). Fora essa pequena introdução, não há qualquer menção aos países de fala alemã ou às indicações do tipo "D-A-CH” que estão presentes no Kursbuch e no Übungsbuch.

As indicações no manual sobre as atividades das lições são bem sucintas, apenas algumas atividades recebem comentários de como conduzir as atividades presentes no Kursbuch, com sugestões de jogos e brincadeiras. As atividades contidas no Übungsbuch não são comentadas pelo manual do professor. Em toda a parte correspondente ao nível A1, foi encontrada somente no início da lição 8 uma indicação de trabalho com as diferenças entre as variedades da língua alemã, mais especificamente no que se refere à variação fonológica e lexical.

Nesse momento o professor pode, caso os aprendizes façam perguntas a respeito, apontar determinadas diferenças na pronuncia do alemão suíço padrão, como por exemplo, a pronúncia de "ch" e "-g" no fim de palavras como "ich", "rechts", "richtig", e o tom mais suave [weicherer Tonfall] que acontece pela falta da oclusiva glotal (Knacklaut), como em "mit dem Auto" (=demauto) e em "geradeaus" (sem oclusiva glotal entre "e-"e "-aus"). Além disso, há algumas poucas variantes lexicais a serem consideradas (cf. coluna marginal) e variantes nas formas de saudação e despedida: por exemplo, "Grüezi!", "Uf Wiederluege“, "Ade!". Em "Ade!" é possível observar diferenças na pronúncia: Falantes mais inclinados ao alemão padrão da Alemanha pronunciam Adé (com ênfase na última sílaba), outros falantes, sob os quais a influência do Schwiizerdütschen é maior, pronunciam Áde, com ênfase na primeira sílaba (SANDER; SCHÄFER 2017: 40, tradução nossa $)^{15}$.

\footnotetext{
${ }^{15}$ Hier kann KL, falls TN danach fragen, auf gewisse Unterschiede in der Aussprache des Schweizer Standarddeutsch hinweisen, wie z. B. die Aussprache des ,,ch“, des „-g“ am Wortende, z. B. ,ich“, „rechts“, „richtig“, und des „weicheren Tonfalls“ durch den fehlenden Knacklaut, wie z. B. „mit dem Auto“ (=demauto) in ,geradeaus“ (kein Knacklaut zwischen „e-“ und „-aus“). Außerdem sind einige wenige Wortschatzvarianten zu beachten (vgl. die Marginalspalte) und Varianten bei den Begrüßungs- und Abschiedsformeln: z. B. „Grüezi!“, „Uf Wiederluege“, „Ade!“. Bei „Ade!“ kann man auch schön die Unterschiede im Wortakzent sehen: Mehr zum deutschen Standarddeutsch neigende Sprecher sprechen es Adé (letzte Silbe betont) aus, andere, bei denen der Einfluss des Schwiizerdütschen größer ist, sprechen es Áde aus, mit der Betonung auf der ersten Silbe.
}

Pandaemonium, São Paulo, v. 23, n. 41, set.-dez. 2020, p. 1-23 
SAVEDRA, M.M.G.; MeIRELleS, C. - Pluricentrismo no ensino de Alemão como Língua Estrangeira

Além disso, três exercícios extra (Kopiervorlage) abordam temas que envolvem os países de fala alemã, um na primeira lição e dois na lição 8. Em um exercício de interação verbal os aprendizes devem fazer perguntas e obter respostas sobre quantas pessoas moram nas cidades universitárias alemãs (Wie viele Einwohner haben die deutschen Universitätsstädte?).

Nos exercícios extras sugeridos para a lição 8 aparecem algumas informações sobre a Suíça, como ilustradas a seguir, assim como um mapa da cidade de Berna (Kopiervorlage 8 A5), na página 44 do manual do professor.

Figura 4 - Kopiervorlage 8 A1

In der Schweiz spricht man Deutsch, Französisch, Italienisch und Rätoromanisch.

Zwei Drittel (66 Prozent) der Schweizer sprechen Deutsch. Ihre Muttersprache ist aber ein deutsch-schweizer Dialekt.
Die Schweizer verwenden kein "ß $B^{\prime \prime}$ Sie schreiben zum Beispiel das Wort Straße mit "ss".

Fonte: SANDER; SCHÄFER (2017: 41)

\section{Considerações finais}

Retomando ao argumento inicial deste artigo, apresentamos uma proposta para análise de categorias de pluricentrismo linguístico em um material didático para ensino de ALE no Brasil - DaF Kompakt neu A1, mais especificamente, para o ensino de LA nas três universidades do estado do RJ que oferecem cursos de licenciatura em Letras PortuguêsAlemão.

Ao investigar a presença das seis categorias de análise propostas (competência, tema, tipo de fonte de texto, tópicos discursivos de pluricentricidade, abordagem e variedade pluricêntrica) no DaF kompakt neu $A l$ identificamos algumas tendências que emergiram como relevantes para discutir o tema pluricentrismo no ensino de ALE.

Quanto às três categorias que foram propostas a partir do disposto no QECR, identificamos que o tema do pluricentrismo é abordado com maior incidência nas competências receptivas do que nas produtivas. O que se justifica pelo nível de proficiência analisado. No que se refere ao tema, textos da área (SHAFER 2018; MAIJALA 
SAVEDRA, M.M.G.; MeIRELleS, C. - Pluricentrismo no ensino de Alemão como Língua Estrangeira

2007) normalmente apontam a tendência de se relacionar uma abordagem pluricêntrica com estereótipos sobre os países de língua alemã, incluindo temas como turismo e alimentação. No caso de nossa análise, embora tenhamos reconhecido a presença desses temas, não identificamos a predominância de temas específicos. A terceira categoria que se baseou no QECR apontou o tipo de fonte: textos autênticos, semi-autênticos e não autênticos. Neste quesito identificamos que a maioria dos textos que abordam a temática do pluricentrismo tende para o tipo semi-autêntico.

Quanto às categorias restantes que se basearam no DACH-Prinzip (tópicos discursivos de pluricentricidade, abordagem e variedades pluricêntricas), observamos que o tema pluricentrismo é abordado a partir da variedade da Alemanha. Os exercícios que introduzem variantes lexicais da Alemanha o fazem de forma implícita. Em contrapartida atividades com variantes lexicais da Suíça e Áustria apontam de forma explícita a diferença entre as variantes suíças e austríacas em comparação com as variantes da Alemanha. Seria interessante e bastante produtivo que as variantes específicas da Alemanha fossem apresentadas como tais, e não sem indicação explícita, visto que pode gerar um desentendimento no que diz respeito às variantes específicas e gemeindeutschvariantes comuns a todos os países de fala alemã.

Embora tenhamos apenas realizado a investigação no livro que corresponde ao nível A1 do QECR, afirmamos ser importante que tal análise seja ampliada para os demais livros da série (A2 e B1), como também para os demais materiais de ensino de ALE.

A pluricentricidade da LA deve ser considerada no ensino de ALE, em especial nos cursos de formação de professores, local por excelência de formação de profissionais que irão atuar no magistério e, portanto, serão multiplicadores deste conhecimento. Os estudos mais recentes que apresentamos neste artigo, bem como a inserção do tema nos congressos da área justificam nossa afirmação e apontam para a relevância da continuidade e aprimoramento da pesquisa na área, tanto nos cursos de graduação como de pós-graduação.

\section{Referências bibliográficas}

ABCD-Thesen zur Rolle der Landeskunde im Deutschunterricht. In: Fremdsprache Deutsch, n. 5, p. 306-308, 1990. 
SAVEdRA, M.M.G.; MeIRELlES, C. - Pluricentrismo no ensino de Alemão como Língua Estrangeira

AltmaYer, C. Die DACH-Landeskunde im Spiegel aktueller kulturwissenschaftlicher Ansätze. In: DeMmig, S.; HÄGI, S.; SCHWEIGER, H. (orgs.). DACH-Landeskunde. TheorieGeschichte-Praxis. München: Iudicium, 2013, p. 15-21.

AltmaYer, C. et al. (org.) Mitreden. Diskursive Landeskunde für Deutsch als Fremd- und Zweitsprache. Stuttgart: Ernst Klett Sprachen, 2019.

AMMON, U. Towards a descriptive framework for the status/function (social position) of a language within a country. In: AMMON, U. (org.). Status and Function of Languages and Language Varieties. Berlin/New York: Walter de Gruyter, 1989, p. 21-106.

AMmon, U. Die deutsche Sprache in Deutschland, Österreich und der Schweiz. Das Problem der nationalen Varietäten. Berlin/New York: De Gruyter, 1995.

AMMON, U. et al. (org.). Variantenwörterbuch des Deutschen. Die Standardsprache in Österreich, der Schweiz, Deutschland, Liechtenstein, Luxemburg, Ostbelgien und Südtirol sowie Rumänien, Namibia und Mennonitensiedlungen. 2. ed. Berlin: De Gruyter, 2018.

AUER, P. Enregistering pluricentric German. In: SOARES DA SILVA, A. (org.) Pluricentricity: Language Variation and Sociocognitive Dimensions. Berlin/Boston: De Gruyter, 2014, p. 19-48.

BRAUn, B. et al. DaF kompakt neu A1. Kurs- und Übungsbuch mit MP3-CD. Stuttgart: Ernst Klett Sprachen, 2016.

Clyne, M. Pluricentric Languages: Differing Norms in Different Nations. Berlin/New York: De Gruyter, 1992.

Clyne, M. Pluricentric Language / Plurizentrische Sprache. In: AMMON, U.; MATTHEIER, K.; TrudGILl, P. (org.). Sociolinguistics/Soziolinguistik. 2. ed., v. 1, Berlin: De Gruyter, 2004, p. 296-300.

CONSELHO DA EUROPA. Quadro europeu comum de referência para as línguas: Aprendizagem, ensino, avaliação. Porto: Edições ASA, 2001.

DEMmig, S.; HÄGI, S.; SCHWEIGER, H. (orgs.). DACH-Landeskunde. Theorie - Geschichte Praxis. München: Iudicium, 2013.

Drumbl, H.; Carvalho, G.: KlinNer, J. (orgs.). IDT 2013 Band 8 - Sprachenpolitik und Sprachenvielfalt. 1.ed. Bolzen-Itália: Bozen-Bolzano University Press, v. 1, 2016.

FAISTAUER, R. Die sprachlichen Fertigkeiten. In: KRUMM, H. et al. (org.) Deutsch als Fremdund Zweitsprache: Ein internationales Handbuch. Berlin/New York: De Gruyter, 2010, p. 961-969.

FISCHER, R.; FRISCHHERZ, B.; NOKE, K. DACH-Landeskunde. In: KRUMM, H. et al. (org.) Deutsch als Fremd- und Zweitsprache: Ein internationales Handbuch. Berlin/New York: De Gruyter, 2010, p. 1500-1511.

HÄGI, S. Aber bitte richtig mit Sahne, Rahm oder Schlag(obers): Voraussetzungen für eine adäquate Umsetzung des plurizentrischen Ansatzes im DaF-Unterricht. In: ABEL, A.; StUflesser, M.; PUTZ, M. (org.). Mehrsprachigkeit in Europa. Erfahrungen, Bedürfnisse, Gute Praxis. Bolzano/Bozen: Europäische Akademie Bozen, 2006, p. 273284.

IDV. DACH-Prinzip. 2013. Revidierte Fassung der ursprünglichen Version 2008 (angenommen im Rahmen der Sitzung der DACH(L)-Arbeitsgruppe innerhalb des IDV am 14. November 2008 in Zürich). Disponível em: http://idvnetz.org/dachl-online/dachl-imfach-dafdaz/dach-prinzip. Acesso em: 15 ago. 2019.

JARZĄBEK, A. Der plurizentrische Ansatz und das DACH-Prinzip in polnischen DaFLehrwerken. In: Germanica Wratislaviensia, v. 138, p. 173-183, 2013a.

JARZĄBEK, A. IDV-Internationaler Deutschlehrerverband. In: DEMMIG, S.; HÄGI, S.; SCHWEIGER, H. (orgs.). DACH-Landeskunde. Theorie - Geschichte - Praxis. München: Iudicium, 2013b, p. 155-160.

Pandaemonium, São Paulo, v. 23, n. 41, set.-dez. 2020, p. 1-23 
SAVEdRA, M.M.G.; MeIRELlES, C. - Pluricentrismo no ensino de Alemão como Língua Estrangeira

KLOSS, H. Abstandsprachen und Ausbausprachen. In: GÖSCHEL, J.; NAIL, N.; VAN DER ELST, G. (org.). Zur Theorie des Dialekts. Wiesbaden: Steiner, 1976, p. 301-322.

KRUMM, H. Lehrwerke im Deutsch als Fremd- und Deutsch als Zweitsprache-Unterricht. In: KrumM, H. et al. (org.). Deutsch als Fremd- und Zweitsprache: Ein internationales Handbuch. Berlin/New York: De Gruyter, 2010, p. 1215-1227.

KrumM, H. Von ABCD zu DACHL. IDV-Magazin. v. 92, 2017, 6-12. Disponível em: https://idvnetz.org/publikationen-des-idv/idv-magazin-92. Acesso em 20 ago. 2019.

Lagares, X. Qual Política Linguística? Desafios Glotopolíticos Contemporâneos. São Paulo: Parábola, 2018.

MAIJALA, M. Was ein Lehrwerk können muss -Thesen und Empfehlungen zu Potenzialen und Grenzen des Lehrwerks im Unterricht Deutsch als Fremdsprache. In: Informationen Deutsch als Fremdsprache, v. 34, n. 6, p. 543-561, 2007.

PupP SPINASSÉ, K.; BREDEMEIER, M. Institutionelle Perspektiven auf DACH: ABraPA Associação Brasileira de Associações de Professores de Alemão (Brasilianischer Deutschlehrerverband). In: DEMming, S.; HÄGI, S.; SCHWEIGER, H. (org.) DACHLandeskunde: Theorie - Geschichte - Praxis. München: Iudicium, 2013, p. 191-195.

RIESEL, E. Der Stil der deutschen Alltagsrede. Leipzig: Reclam, [1964] 1970.

RÖSLER, D. Deutsch als Fremdsprache. Eine Einführung. Stuttgart: Metzler, 2012.

SANDER, I.; SCHÄFER, N. DaF kompakt neu A1-B1. Lehrerhandbuch. Stuttgart: Ernst Klett Sprachen, 2017.

SAVEDRA, M. Das plurizentrische Deutsch in Brasilien als Kommunikationsmittel im DaF- und DaZ-Bereich. In: Drumbl, H.; CARVAlHo, G.: Klinner, J. (orgs.). IDT 2013 Band 8 Sprachenpolitik und Sprachenvielfalt. 1.ed. Bolzen-Itália: Bozen-Bolzano University Press, 2016, v. 1, p. 141-150.

SAVEDRA, M.M.G. A língua pluricêntrica alemã em variedades dialetais no contexto plurilíngue do Brasil. In: SAVEDRA, M.M.G.; MARTins, M.A.; DA HorA, D. Identidade social e contato linguístico no português brasileiro. Rio de Janeiro: Eduerj, 2015, p. 147-164.

SHAFER, N. Varietäten und Varianten verstehen lernen: Zum Umgang mit Standardvariation in Deutsch als Fremdsprache. Band 99 - Materialien Deutsch als Fremd- und Zweitsprache, Universitätsverlag Göttingen, 2018.

SIG 2.4. Deutsch als Sprache des deutschsprachigen (Diskurs- und Kultur-)Raums: Vermittlung der sprachlichen und kulturellen Pluralität des DACHL-Raums in DaF, 2017. Disponível em: https://www.idt-2017.ch/images/03_fachprogramm/02_sig/Bericht_SIG_2.4_ Plurizentrik.pdf. Acesso em: 21 out. 2019.

SORGER, B. Institutions- und sprachenpolitische Aspekte des DACH-Konzepts. In: DEMMIG, S.; HÄGI, S.; ScHWEIGER, H. (orgs.). DACH-Landeskunde. Theorie - Geschichte - Praxis. München: Iudicium, 2013, p. 32-48.

SPIEKERMANN, H. Variation in der deutschen Sprache. In: KRUMM, H. et al. (org.) Deutsch als Fremd- und Zweitsprache: Ein internationales Handbuch. Berlin/New York: De Gruyter, 2010, p. 343-360.

UPHOFF, D. O poder do livro didático e a posição do professor no ensino de alemão como língua estrangeira. Tese de doutorado. Campinas: IEL/Unicamp, 2009.

Recebido em 17 de novembro de 2019 Aceito em 11 de março de 2020

Pandaemonium, São Paulo, v. 23, n. 41, set.-dez. 2020, p. 1-23 